\title{
La formación, el desarrollo y la transformación radical en Europa de la Jurisdicción contencioso-administrativa
}

\author{
Eduardo García de Enterría
}

Catedrático de Derecho Administrativo

\section{Resumen:}

El estudio analiza el origen y evolución de la justicia administrativa con especial incidencia en el papel desempeñado por el Consejo de Estado y en las transformaciones que se producen en Francia como consecuencia de un conjunto de Leyes dictadas en los últimos años del siglo XX finalmente ordenadas en un novedoso Código de la Justicia Administrativa y que afectan de manera sustancial a la tutela cautelar y al valor de las sentencias estimatorias de los recursos. Igualmente constata la generalización del control de la jurisdicción contencioso-administrativa en toda Europa.

Abstract: The study analyses the origin and development of administrative justice, with special emphasis on the role played by the Council of State and on the changes that arise in France as a result of the laws passed at the end of the twentieth century to finally organize an innovative Code for Administrative Justice. This substantially affected precautionary protection and the value of the final rulings on appeals. Similarly, it states the generalisation of reinforced control on behalf of administrative contentious proceedings throughout Europe.

\section{Palabras clave:}

Ley, legalización del poder, control judicial de la actuación administrativa, tutela cautelar, valor de las sentencias estimatorias de los recursos.

Key words: Law, legalisation of power, judicial control of administrative proceedings, precautionary protection, value of final rulings on appeals.

Excmo. Sr. D. Presidente de la Real Academia de Jurisprudencia y Legislación de Sevilla. 


\section{Excmos. Sres. Académicos}

Sras y Sres.

Mis primeras palabras deben de expresar mi gratitud profunda y emocionada por el altísimo honor que me habéis conferido con el nombramiento de Académico de honor de esta prestigiosa e histórica Real Academia Sevillana.

Pienso que es, evidentemente, obra del afecto de tantos académicos amigos y colegas que aquí tengo. Pero para mí, que vengo de los rudos y lejanos montes cántabros, significa, al lado del honor académico, la singularidad de hacerme casi un sevillano de adopción, la de formalizar, pues, casi un status de andaluz, siquiera sea honorario. Soy uno más de los hombres de la dura España del norte que estamos seducidos y ganados por esta tierra andaluza y por esta prodigiosa y mágica ciudad. Pienso que tengo ya desde ahora, por generosidad vuestra, un vínculo moral que de algún modo me vincula formalmente a este lugar fascinante y mágico que es Sevilla.

Aunque el honor me ha sido conferido formalmente por la Corporación, me atrevo a imaginar que en su seno ha actuado de forma cualificada mi admirado colega, el Profesor Manuel Clavero Arévalo, [que ahora ha hecho ante Vds. lo que es una verdadera "Laudatio"], un hombre clave no sólo en Sevilla y en toda Andalucía, sino también en el nuevo Derecho Administrativo surgido a mitad del siglo XX y cuyo órgano más relevante sería la "Revista de Administración Pública”, que ha cumplido ya 60 años, casi los de su condición de Catedrático de Derecho Administrativo, que ganó con una sorprendente juventud, que veo con placer que mantiene íntegra.

!Muchas gracias a todos los miembros de esta vivísima Real Academia sevillana!

Para aportar una respuesta adecuada a este acto académico voy a exponer a continuación una pequeña reflexión sobre un tema de actualidad para los iuspublicistas, el asombroso salto cualitativo que en este cambio de siglo XX-XXI ha venido a experimentar el sistema específico de garantías de los derechos ciudadanos que es la jurisdicción contencioso-administrativa en toda Europa.

Uno de los más grandes y duraderos legados de la Revolución Francesa fue, sin duda, la implantación resuelta y rigurosa del principio de legalización general de la Administración y de toda su actuación. En la primera de las 
Constituciones revolucionarias, la de 1791 (art. 4 de la Sección II del Capítulo IV del Título III -la numeración de los artículos no es sucesiva en esta Constitución, sino propia de cada uno de sus varios títulos, capítulos y secciones) dice:

"Pertenece al poder legislativo determinar las reglas y el modo en que los administradores ejercen sus funciones".

"No hay en Francia autoridad superior a la Ley. El Rey no reina más que por ella y no es sino en nombre de la Ley como puede exigir obediencia”.

Y precisa en el art. $4^{\circ}$, Sección $2^{\mathrm{a}}$ del Capítulo IV del Título III como una de las funciones del poder legislativo es la de "determinar las reglas y el modo de sus funciones [de los administradores]... sobre todas las partes de la Administración interior".

La justicia administrativa fue una más de las grande innovaciones institucionales introducidas por la Revolución Francesa, que, como tantas otras, fue puesta a punto por su principal ejecutor testamentario, Napoleón Bonaparte.

Fue una creación jurídica enteramente nueva, que carecía de raíces en los grandes fundamentos históricos en que hasta entonces se había arraigado todo el Derecho europeo (Derecho Romano, Derecho Germánico, ius commune medieval o moderno, el common law, el Derecho Natural y de Gentes). Surge súbitamente en la Revolución en el mismo año 1789, en que comienza su formidable innovación, se afirma y madura a lo largo del Siglo XIX y conoce un espectacular despliegue a lo largo del XX, presentándose ahora, recién inaugurado el siglo XXI, tras las reformas generalizadas en el último cambio de siglo y comienzos del actual, como una pieza central del orden democrático sustantivo, lo que se ha convenido en llamar Estado de Derecho.

La justicia administrativa aparece como algo nuevo que pone en pie la Revolución Francesa para intentar hacer real, con una sorprendente lucidez y resolución, uno de los principios básicos formulaos por Locke y por Rousseau, "poner a la Ley por encima del hombre". Nadie puede ejercer el poder en una sociedad de hombres libres si no es en virtud de la Ley, dijo Rousseau: "Un pueblo libre obedece pero no sirve; tiene jefes pero no dueños; obedece a las Leves, pero nada más que a las Leves, y es por la fuerza de las Leves por lo que no obedece a los hombres". 
Y concluye Rousseau este pasaje capital de sus Lettres écrites de la Montagne:

"Un pueblo es libre, sea cual sea la forma de su gobierno, cuando en quien le gobierna no ve al hombre, sino al órgano de la Ley. En una palabra, la libertad sigue siempre la suerte de las Leves, reina o perece con ellas: yo no sé nada que sea más cierto”.

Esta idea esencial pasará a la capital Declaración de Derechos del Hombre y del Ciudadano de 1789, con la que se inaugura significativamente la obra jurídica de la Revolución Francesa. El art. $5^{\text {a }}$ de esta Declaración proclama:

"Todo lo que no está prohibido por la Ley no pude ser impedido y nadie puede ser forzado a lo que la Ley no ordena".

Y en el art. $7^{\circ}$, a propósito del poder punitivo, establece el principio básico de que "nadie puede ser juzgado ni condenado más que en los casos determinados por la Ley y según las formas que ella prescribe", para concluir:

"sólo cuando un ciudadano es llamado a obedecer en virtud de la Ley debe obedecer al instante".

Todos estos principios producen el impresionante fenómeno histórico, completamente decisivo para entrar en la modernidad, de la legalización general del poder y de la obediencia, lo que será llamado expresivamente "el reino de la Ley" (expresión que se inscribirá en las primeras monedas revolucionarias).

Toda la tradición que había precedido ese momento revolucionario consideraba al aparato administrativo como un simple instrumento personal del monarca, el cual monopolizaba además el poder legislativo, aunque él mismo se proclamase legibus solutus, absuelto, libre de la Ley, que él podía utilizar para quebrantar derechos anteriores y otorgar exenciones, para crear nuevo Derecho, sin límites jurídicos efectivos.

La Revolución opera así uno de sus capitales cambios en el sistema jurídico: la Ley deja de ser un simple instrumentum regni, con el que el Príncipe podía quebrantar cualquier derecho de sus súbditos, según se había entendido hasta entonces, y pasa a ser ahora precisamente el instrumento que define y delimita la extensión y el contenido del propio poder real o del ejecutivo, en la nueva terminología impuesta por el principio de la división de poderes. La 
Administración va a pasar ahora a ser, en virtud también de ese capital principio de división de los poderes, que proclamó el art. 16 de la misma Declaración de Derechos del Hombre, una organización llamada a la ejecución de la Ley, la cual previamente ha determinado su organización, su competencia, los objetivos de su actuación, los límites concretos de su poder.

Este sometimiento de la Administración a la Ley para ser efectivo necesitará de una garantía eficaz. El propio Rousseau, después de haber proclamado, como ya hemos visto, el principio básico de sometimiento de toda la actuación del Estado a la legalidad, añade:

\section{"no habrá libertad en un Estado en el que el cuerpo encargado de aplicar la Ley tuviese derecho a hacerla hablar según sus fantasias, pues podría ejecutar como Leves sus voluntades más tiránicas".}

Por ello, la Declaración de Derechos de 1789, que inaugura la obra jurídica de la Revolución Francesa, en su art. 15, se ve obligada a establecer rotundamente el capital principio de la responsabilidad política y personal de todos cuantos ejerciesen un poder político, en estos términos:

"La sociedad tiene el derecho de pedir cuentas a todo agente público de su Administración".

El art. 16 de la Declaración subraya el carácter esencial del principio (subrayando su significación con el dogmático y capital principio de división de los poderes):

"Toda sociedad en la cual la garantía de los derechos no haya sido asegurada ni la separación de poderes establecida no tiene Constitución".

Ese aseguramiento de los derechos exige, pues, una "dación de cuenta" de los agentes, lo que hace que éstos no sean ya más propietarios de sus oficios, como ocurría en el Antiguo Régimen. Pasarán a ser ahora, como explicó Locke, trustees, ligados por un trust o relación de confianza con el pueblo, ante el cual deberán responder (la palabra "responsabilidad" surge con ese sentido de dación de cuenta justo en el momento mismo de la Revolución en todas la lenguas).

Como ya vimos más atrás, con la Constitución de 1791, la primera de los revolucionarios franceses, se precisa que: 
"Pertenece al poder legislativo [esto es, a la Ley] determinar las reglas y el modo en que los administradores ejercen sus funciones".

Y en el art. $3^{\circ}$, Sección Primera, capítulo II, título III:

\section{"No hay en Francia autoridad superior a la de la Ley. El Rey no reina más que por ella y sólo en nombre de la Ley puede exigir la obediencia".}

Se hace aquí visible el momento fundacional del moderno Derecho Público, fundamentado en la resuelta extensión de la Ley, no ya sólo a la organización de la Administración (que eso ya lo había hecho el Antiguo Régimen), sino, y sobre todo, al contenido entero de su competencia y de todas las formas del ejercicio del poder que ejerce.

Aunque la propia Constitución ha previsto una sanción penal a la inobservancia por los administradores de esa vinculación a la Ley (art. 8 de la misma Sección $3^{\mathrm{a}}$ del Capítulo $4^{\circ}$, dedicada a la Administración interior), lo más característico va a ser lo que el art. $5^{\circ}$ de la misma sección y capítulo establece en favor del Rey como poder formal el "derecho de anular los actos de las Administraciones de Departamento contrarias a las Leves y a las órdenes que el propio Rey les haya dirigido".

Esa anulación no podía confiarse al poder judicial porque estaba ya establecido el capital principio de separación entre la Administración y la Justicia con anterioridad a la Constitución, por la básica Ley de 16-24 de agosto de $1790^{1}$, que marcará todo el sistema político francés hasta hoy mismo, y que dispuso:

"Los Tribunales no pueden inmiscuirse en el ejercicio del Poder Legislativo o suspender la ejecución de las Leyes, ni intervenir [troubler, molestar] sobre las funciones administrativas o citar ante ellos a los administradores por razón de sus funciones".

\footnotetext{
${ }^{1}$ En realidad esta Ley venía ya exigida por la Administración del Antiguo Régimen. (Vivien, en sus Eludes administratives, $3^{\mathrm{a}}$ ed. París, 1845, pág. 20, dice: "El primer cuidado de la Asamblea Constituyente en el momento en que ella misma fundaba el régimen nuevo" fue declarar que "las funciones judiciales son distintas y deberán permanecer siempre separadas de las funciones administrativas" y decidió que "los jueces no podrán, bajo pena de prevaricación, molestar-"troubler"--de cualquier manera las operaciones de los cuerpos administrativos ni citar ante ellos a los administradores por razón de sus funciones". Ley que no sólo ha sido mantenida en vigor hasta hoy mismo, sino que el Conseil Constitutionnel de la V República la ha reconocido de rango constitucional en fechas bien recientes.
} 
Este criterio está ya recogido en el propio texto constitucional de 1791 (en particular: art. 3 del capítulo V), lo que determinará que la Constitución defina como una facultad explícita atribuida al mismo Poder ejecutivo -no, pues, a los jueces- la de anular los actos de la Administración "contrarios a la Ley o a las órdenes que la autoridad de ese Poder, el Rey [con el Gobierno], les hubiera dirigido" (art. $5^{\circ}$ de la Sección II, capítulo IV del Título III), poder que se atribuye a la Administración central respecto de las administraciones de distrito (art. 5) y a éstas últimas sobre los actos de los "subadministradores de distrito" o municipales. Aquí está el primer esbozo de una jurisdicción contencioso administrativa, jurisdicción, evidentemente, estrictamente "retenida" en las manos de la propia Administración.

Esta jurisdicción, sin embargo, comenzará a formalizarse como tal con la primera Constitución napoleónica, la del año VIII (1799), que crea en el art. 52 un Conseil d'Etat, Consejo de Estado al que se encomienda redactar los proyectos de Ley y los reglamentos de Administración pública y "resolver las dificultades que surjan en materia administrativa". Es esta última función la que va a hacer del Consejo de Estado desde ese mismo momento, hasta hoy mismo, la pieza esencial que configura para varios siglos el sistema francés de justicia administrativa, que marca el origen del sistema contencioso-administrativo, como comenzará a precisar el Reglamento de ese órgano de 26 de noviembre de 1799, cuyo art. 72 establece el básico principio de responsabilidad de los ministros por los actos que adopten "si son contrarios a la Constitución, a las Leyes y a los Reglamentos", según la básica concepción revolucionaria del principio del sometimiento de los actos a la estricta legalidad.

En desarrollo de esos principios, la Ley napoleónica de 28 pluvioso del año VIII especifica y regula por primera vez los órganos administrativos a los que se va a encomendar el conocimiento de los recursos contra los posibles actos de la Administración, que la ya mencionada Ley de separación entre la Administración y la Justicia había excluido, como vimos, que pudiesen ser órganos judiciales formalmente tales. Estos dos órganos administrativos serán el Conseil d'Etat para los actos de las autoridades centrales de la Administración, y los Consejos de Prefectura para los actos emanados de las autoridades del departamento o provincia, autoridades éstas últimas que tenían ya atribuida la facultad de controlar también los actos de los municipios y arrondisse-ments; por otra parte, las decisiones de los Consejos de Prefectura serían, a su vez, apelables ante el Consejo de Estado, que venía a asegurar así un control plenario sobre todos los actos de la Administración, imponiendo la unidad de la interpretación y aplicación de las Leyes. Es la primera piedra de la formidable construcción histórica que han sido la jurisdicción contencioso administrativa 
y el Derecho Administrativo mismo, surgido justamente como un subproducto de la misma.

En 1806 se organiza ya en el seno del Consejo de Estado una Comission du contentieux y se dictan las primeras normas de procedimiento para estos asuntos, que quedan ya orgánicamente separados de las funciones consultivas que eran propias del Consejo en la materia administrativa general, como ha continuado hasta hoy.

Se especializan así en el seno de los órganos consultivos los que asumirán la materia contencioso administrativa. Es el sistema llamado de la justicia retenida, puesto que la decisión final correspondía al Emperador oyendo al Consejo de Estado. Desaparecidos en 1870 los dos Imperios, se atribuirá en 1872 el poder de decisión al Consejo de Estado mismo, que actuará, a partir de ahora como jurisdicción delegada, asumiendo por sí solo la responsabilidad entera de la decisión. La notable calidad de la jurisprudencia de este órgano técnico da lugar a una doctrina nueva, a la que se llamará justamente Derecho Administrativo, articulada sobre el principio básico de la sujeción de la Administración a la Ley, Derecho que se desarrolla teóricamente ya desde la tercera década del siglo XIX. Este ordenamiento singularizado alcanza su culminación al jurisdiccionalizarse enteramente el Consejo de Estado en 1872 (sin perjuicio de mantener separada la función consultiva a la que debe su nombre). Lo que, como ya indicamos, dio lugar al sistema de jurisdicción delegada o independiente. El comentario y sistematización de esta jurisprudencia, cada vez mas motivada y sutil, da contenido y rigor institucional a esta nueva rama del Derecho, que conocerá un perfeccionamiento y depuración sucesivos. En el origen este sistema estructura y da sentido a los criterios que la jurisprudencia del Consejo de Estado va depurando, cada vez con una substancia institucional más explícita y firme.

La justicia administrativa acierta así a poner en pie un sistema jurídico que carecía de precedentes en la larga evolución de los sistemas políticos y jurídicos europeos y que terminará caracterizándose, y así continúa, como una pieza esencial del actual Estado de Derecho.

\section{II}

De este sistema de justicia administrativa destacará resueltamente el llamado recurso de anulación, creación nueva enteramente jurisprudencial. El Consejo de Estado, que conocerá -recurso de plena jurisdicción- los recursos 
que los particulares le dirigen en sustitución de los jueces ordinarios en materias de derecho privado, o en las que la Administración actúa en posición de igualdad con los administrados, recursos que la regla básica de la separación con la justicia impedía que fuesen conocidos por los jueces y tribunales ordinarios, comienza a admitir además recursos en los que se reprocha a la Administración una actuación groseramente ilegal en sus fundamentos, aunque el recurrente no exhiba un verdadero derecho en la materia. La calidad administrativa del Consejo de Estado le hace sensible a lo que podría considerarse como una mera denuncia de una actuación completamente irregular, de "orden público", como se dirá en España en el momento de su temprana recepción con el mismo sistema de atribuir el papel central a la misma pieza esencial del Consejo de Estado, creado en España a esos fines. Terminará por exigirse al recurrente una qualité pour agir o legitimación, que es un interés en el recurrente, interés que se concibe ahora como mera "exigencia de seriedad", y que no tendrá en el fallo del proceso ninguna transcendencia (incluso si el recurrente hubiese desistido del recurso tras haber puesto en marcha el proceso, éste continuará hasta la Sentencia). Se creó así un recurso que será calificado de "objetivo", en el que el recurrente, dirá aún Hauriou ya entrado el siglo XX, actúa al modo de un Ministerio Fiscal, en interés de la legalidad.

La consagración de un sistema de jurisdicción contencioso administrativo delegada, esto es, decidiendo ejecutoriamente por propia autoridad, y tras un corto período de tiempo en 1849 , no tiene lugar, como dijimos, hasta la Ley de 5 de mayo de 1872, fecha a partir de la cual el desarrollo del sistema será esencialmente jurisprudencial prácticamente hasta finales del siglo XX, como veremos.

La depuración constante de esta jurisprudencia, matizada y perfeccionada por un Consejo de Estado objeto de un culto y una admiración sin fisuras, hizo del sistema contencioso administrativo francés, y dentro de él del recurso de anulación, el paradigma mismo de la excelencia. En 1929 la gran autoridad de Gastón Jéze decía: "el excés de pouvoir es la más maravillosa creación de los juristas, el arma más eficaz, la más práctica que existe en el mundo para defender libertades", juicio repetido y desarrollado por las sucesivas generaciones de especialistas y de expertos, sin excepción.

III

Pero he aquí que, de una manera súbita e inesperada, el legislador francés ha irrumpido resueltamente a finales del siglo XX y comienzos del XXI en 
el sistema contencioso administrativo, rompiendo la tradición de dejar su perfeccionamiento, como venía ocurriendo desde hacía dos siglos, a lasage lenteur, la sabia lentitud, de la jurisprudencia del Consejo de Estado, que avanzaba parsimoniosamente por pasos medidos, para pulir cuidadosamente, con una complacencia casi estética, los rasgos de un sistema jurídico que se tenía por la perfección misma, respetada, admirada y amada por jueces, doctrina, justiciables y políticos.

Abruptamente, he aquí que esa creación jurisprudencial tan bien construida y admirada va a ser ahora abierta y sustancialmente desautorizada por un legislador que irrumpe inesperadamente para privar, por de pronto, al Consejo de Estado del monopolio con que venía dirigiendo y perfeccionando la configuración de la pieza clave del sistema, el recurso de anulación, que era su carácter puramente declarativo, en el que se quintaesenciaban y sublimaban limitaciones procedentes de los mismos dogmas revolucionarios primigenios. Las Leyes de 1980 y de 8 de febrero de 1995, más tarde sistematizadas y completadas por otras Leyes de 4 de mayo y 30 de junio de 2000, y ordenadas finalmente en un espectacular y novedoso Código de la Justicia Administrativa, han supuesto, por de pronto, la privación al Consejo de Estado de su protagonismo virtualmente exclusivo sobre la justicia administrativa, procediéndose a una insólita codificación total, absolutamente novedosa, de toda la materia contencioso administrativa.

Pero no se ha tratado de una mera sistematización en una Ley de las creaciones jurisprudenciales de la materia, tan cuidadosamente depurada por el Consejo de Estado, sino de una modificación absolutamente esencial del sistema en dos puntos capitales del mismo, hasta el punto de hacer de él. a partir de ahora, un sistema enteramente nuevo. Esos dos extremos objeto de una transformación sustancial han sido la tutela cautelar y, sobre todo, el valor de las Sentencias estimatorias de los recursos contencioso administrativos, atribuyendo íntegra ahora a la propia jurisdicción contencioso administrativa un poder jurisdiccional plenario, en la misma medida del que disponen todas las jurisdicciones ordinarias y de la que hasta ahora carecía radicalmente el Consejo de Estado, por virtud del principio básico de la "separación" entre la Administración y la justicia, esto es la de ejecución forzosa de sus propias Sentencias, tanto sobre la Administración misma como sobre los administrados afectados por ellas. Se ha puesto así fin espectacularmente a una serie de principios y criterios que habían venido considerándose durante los casi dos siglos de su existencia como esenciales a la jurisdicción contencioso administrativa y al mismo Derecho Administrativo, para establecer ahora una paridad virtualmente absoluta entre esta jurisdicción y las demás jurisdicciones ordinarias. 


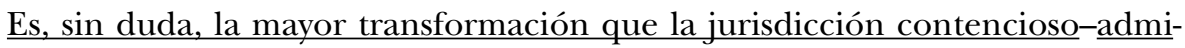
nistrativa ha experimentado en Francia hasta ahora desde sus mismos orígenes. Toda ella ha pasado a ser ahora una jurisdicción plenaria y efectiva, con el abandono resuelto de su limitación al solo plano declarativo y el explícito reconocimiento de su posibilidad de ejecutar forzosamente sus sentencias frente a una Administración renuente.

\section{IV}

Toda esa cuidadosa construcción, obra predilecta de la jurisprudencia del Consejo de Estado, con su sage lenteur, su sabia lentitud, que avanzaba parsimoniosamente por pasos medidos, con una complacencia casi estética, admirada, elogiada y amada por políticos, jueces, justiciables, doctrina universitaria y forense, todo ese impresionante edificio, cuando apenas si existía una crítica de alguna entidad contra el mismo, acaba de ser desautorizada, en efecto, por un legislador que ha irrumpido inesperadamente en la materia, poniendo fin así al protagonismo prácticamente exclusivo del Consejo de Estado sobre esa nueva especie de justicia que él había imaginado, configurado y perfeccionado paciente y sabiamente durante casi dos siglos completos.

Inesperadamente, súbitamente, en efecto, ha irrumpido el Legislador, en los años finales del siglo XX y comienzos del XXI para reconfigurar enteramente el sistema contencioso administrativo francés desde sus mismas bases.

A partir de las Leyes francesas de 16 de julio de 1980 y de 8 de febrero de 1995 se reconfigura resueltamente, en efecto, el sistema, un sistema hasta ahora entregado en exclusiva al Consejo de Estado, poniendo así fin de una manera espectacular al monopolio que éste ha mantenido durante casi dos siglos de la responsabilidad de su concepción y de su desarrollo. Se ha aprobado un insólito Code de Justice Administrative, que es una legalización completa y absoluta de toda la extensión y funcionamiento del sistema, por cierto con una precisión y un detalle como no existe hoy probablemente en ningún otro Estado. Lo más significativo, sin embargo, no es el hecho mismo de esa codificación, con un pormenor y una extensión desconocidas en cualquier otro Derecho, sino el hecho simple de que ese nuevo Código se ha hecho no con una sistematización de la venerada jurisprudencia del Consejo de Estado, sino introduciendo en el sistema un cambio absoluto de los principios básicos sentados por esa jurisprudencia a lo largo de sus dos siglos de existencia. Simplemente dicho, esta innovación legislativa cambia radicalmente los principios mismos 
del sistema contencioso administrativo francés, convirtiendo ahora a los Tribunales contencioso administrativos y al Consejo de Estado mismo en cuanto ejercita su función jurisdiccional en unos tribunales judiciales plenarios, visibles sobre todo en dos terrenos completamente nuevos, la competencia plena para ejecutar sus propias Sentencias, hasta ahora puramente declarativas, haciéndoles, pues, a todos los tribunales de plena jurisdicción, y la disponibilidad de un sistema extraordinariamente rico y matizado de medidas cautelares, que han venido a poner fin al carácter central del principio de ejecutoriedad de las decisiones de la Administración, no afectadas hasta ahora, salvo en excepciones muy señaladas y resueltamente limitadas.

Destaca, con toda evidencia, la conversión de la jurisdicción contencioso administrativa en una jurisdicción "plena", según la categoría de la bien asentada doctrina procesal francesa. El viejo principio de "separación" entre la Administración y los Tribunales, no obstante su énfasis y su papel central en el origen del contencioso administrativo francés, ha desaparecido, simplemente.

Hoy los poderes del juez contencioso administrativo respecto de la Administración como parte en el proceso han pasado a ser exactamente los mismos que los que tiene el juez ordinario en las actuaciones procesales civiles, laborales o penales sobre los ciudadanos de a pie. El juez contencioso administrativo ha dejado de ser pues, un juez limitado y menor, como, no obstante todo el énfasis puesto en la sutileza y rigor de la doctrina del Consejo de Estado, había venido ocurriendo hasta ahora.

Hay que notar que esta radical transformación del sistema jurisdiccional contencioso-administrativo ha tenido lugar también en otros sistemas europeos, y por las mismas fechas, por cierto, como si obedeciese a un verdadero acuerdo internacional (que no ha existido, desde luego) o al menos a una conciencia común y aguda en toda Europa sobre la necesidad de acabar de un golpe con todas las convencionales e históricas limitaciones que atenazaban una jurisdicción que ha dejado con ello de ser un cuadro teórico y exquisito que no afectaba de manera sustancial al papel manifiestamente prepotente con que se configuró la Administración surgida de la Revolución Francesa, que debería seguir "separada" también de la justicia administrativa por su propia y enaltecida esencia de poder.

El juez contencioso administrativo ha dejado así de ser a partir de ahora un juez limitado y menor, como había ocurrido en sus dos siglos de existencia, no obstante el énfasis puesto en la sutileza y rigor de su jurisprudencia, para adquirir desde ahora la integridad de los poderes de cualquier otro juez so- 
bre sus justiciables. Es una modificación absolutamente sustancial que, por cierto, ha venido a coincidir, como si de un misterioso "espíritu del tiempo" se tratase, con transformaciones análogas en las jurisdicciones contencioso administrativas de otros Estados europeos, España entre ellos ${ }^{2}$.

Finalmente, una tercera Ley francesa, la de 30 de junio de 2000, que incluyó en el Código de la Justicia Administrativa una regulación completa y circunstanciada de las medidas cautelares que la jurisdicción es ahora capaz de imponer a la Administración demandada, rompiendo otro de los dogmas convencionales del anterior sistema, el de la inexorable ejecutividad de sus actos, como propios de un verdadero poder público irrestricto frente al cual el ciudadano habría de mantener siempre una posición jurídica secundaria y menor. Hoy la posición del ciudadano discrepante ha dejado de ser una simple tolerancia para pasar a ser la de titular de un verdadero derecho subjetivo a una justicia efectiva, en los términos del art. 6 del Convenio Europeo de Derechos Humanos, que exige, también en la esfera contencioso administrativa, una tutela efectiva en "igualdad de armas" procesales con la Administración, sin que con la misma pueda producirse indefensión alguna, "con todas las garantías", como dice expresamente dicho precepto, aplicable a la materia contencioso administrativa. De este modo el nuevo Código de Justicia Administrativa ha pasado a ser una regulación pormenorizada de la tutela cautelar ejercitable contra la Administración, de manera realmente espectacular, hasta el punto de que un autor cualificado como Rene Chapus ha podido recientemente decir nada menos que esta materia "domina a partir de ahora el Estado de Derecho", esto es, ha alterado por sí sola la posición misma de la Administración en la estructura y las funciones del Estado.

No tendría interés intentar exponer ahora las soluciones (por cierto, virtualmente análogas) a las que en el mismo momento del cambio del siglo XX-XXI han llegado otros países europeos (Italia, Portugal, Alemania, España), sin que ningún convenio o decisión comunitarias o de otro carácter les

\footnotetext{
${ }^{2} \mathrm{Al}$ incluir la Constitución entre los poderes propios de toda jurisdicción el poder de ejecución de las Sentencias que dicte (art. 117.3), y ser la jurisdicción contencioso-administrativa una verdadera jurisdicción, como resulta también del principio de "unidad jurisdiccional" que proclama el mismo art. 117 en su apartado 5, y precisa el art. 9.4 de la Ley Orgánica de Poder Judicial.
} 
obligase a ello. Como en pocas ocasiones, el "espíritu del tiempo" parece haber obrado por sí solo para que todos viniesen a coincidir en soluciones similares de fortalecimiento de la jurisdicción contencioso administrativa, especialmente en cuanto a la superación definitiva del carácter meramente declarativo de sus sentencias, reconociendo a sus Tribunales las mismas facultades de ejecución forzosa de que gozan los Tribunales como propias de la jurisdicción, así como, un poder nuevo de graduar y hasta excluir la ejecutoriedad autoritaria de los actos revisados mediante un matizadísimo sistema de medidas cautelares.

En Inglaterra, ello está siendo el resultado de su capital Human Rights Act de 1998, con vigencia plena a partir del principio del año 2000, que ha convertido en norma interna la totalidad del Convenio Europeo de Derecho $\mathrm{Hu}-$ manos, con su capital art. $6^{\circ}$, al que ya nos hemos referido ${ }^{3}$.

El ciudadano ha ganado con ello la superación definitiva de su viejo status de "administrado" pasivo frente a una Administración superior, de cualidad más alta, armada de sus tradicionales privilegios y preeminencias de poder público. El sistema de la justicia administrativa ha elevado manifiestamente su rango de ciudadano, al ser ya capaz de contender "con igualdad de armas" con la vieja Administración heredera directa del Rey absoluto.

Los derechos que el ciudadano ostenta en la compleja sociedad actual, derechos hoy enriquecidos por el sustancial de no poder ser afectado en los intereses materiales y morales de su existencia, sobre los que se fundamenta su esencial posición jurídica de hombre libre e independiente, si no es en virtud de una Ley, han quedado sustancialmente elevados. Hoy el juez contencioso tiene la obligación estricta de tutelar en su plenitud ese espacio sustancial de libertad, sólo desde el cual puede el hombre de hoy ser capaz de construir y proteger una vida personal primaria, en su integridad.

La evolución ha conducido, pues, a la conquista definitiva de una jurisdicción plenaria y efectiva para garantizar de manera completa y plenaria, por

\footnotetext{
${ }^{3}$ Baste notar, aunque sea una simple alusión, que esa revolucionaria innovación está suponiendo la rectificación en bloque de su tradicional sistema de Administrative Justice, que partiendo del principio básico del common law que exige un específico writ específico para cada tipo de acción había dado lugar a ¡más de 2000! Administrative Tribunnais, de intervención obligada antes de poder pasar a los recursos jurisdiccionales propiamente dichos. Me parece este dato, por sí solo, una verdadera reducción al absurdo del sistema.
} 
primera vez en la historia, los derechos y libertades de los ciudadanos frente a una Administración que había acertado a mantenerse en una inmunidad sustancial última, en virtud de viejos y convencionales mitos cuidadosamente presentados como supuestamente derivados de "la naturaleza de las cosas" y que escondían, simplemente, la conveniencia y la comodidad práctica de los administradores. 